\title{
Synthesis Design
}

\section{Construction of Large-Area Uniform Graphdiyne Film for High-Performance Lithium-Ion Batteries}

\author{
Jianjiang $\mathrm{He}^{\left[{ }^{[a]}\right.}$ Kaijing Bao, ${ }^{[b]}$ Weiwei Cui, ${ }^{[\mathrm{c}]}$ Jiaojiao $\mathrm{Yu}^{\left[{ }^{[a]}\right.}$ Changshui Huang, ${ }^{*[a]}$ \\ Xiangyan Shen, ${ }^{\text {[a] }}$ Zili Cui, $^{\text {[a] }}$ and Ning Wang ${ }^{[a]}$
}

\begin{abstract}
Large-area graphdiyne film is constructed by heat treatment, including thermally induced evaporation and a cross-coupling reaction process. The growth mechanism is proposed based on the observation and characterization that the heating temperature plays an important role in the evaporation of oligomers and in triggering the thermal cross-coupling reaction, whereas the heating duration mainly determines the execution of the thermal cross-coupling reaction. By controlling the heat-treatment process, a graphdiyne film with uniform morphology and good con-
\end{abstract}

ductivity is obtained. The improved GDY film based electrodes deliver good interfacial contact and more lithium storage sites; thus leading to superior electrochemical performance. A reversible capacity of $901 \mathrm{mAhg}^{-1}$ is achieved. Specifically, the electrodes exhibit excellent rate performance, with which a capacity of $430 \mathrm{mAhg}^{-1}$ is maintained at a rate as high as $5 \mathrm{Ag}^{-1}$. These advantages mean that the uniform graphdiyne film is a good candidate for the fabrication of a flexible and high-capacity electrode material.

\section{Introduction}

Graphdiyne (GDY), as a new 2D carbon allotrope with $\mathrm{sp}^{2}$ - and sp-hybridized carbon atoms, has received tremendous attention due to its high performance in many applications, such as photocatalysis, ${ }^{[1]}$ electrocatalysis, ${ }^{[2]}$ solar cells, ${ }^{[3]}$ oil/water separation, ${ }^{[4]}$ supercapacitors, ${ }^{[5]}$ and lithium-ion batteries (LIBs). ${ }^{[6]}$ This unique atomic structure endows GDY with a $\pi$-conjugated 2D layer plane, uniformly distributed pores, and good conductivity, which play important roles in electrochemical performance. ${ }^{[7]}$ Many theoretical calculations have predicted the high capacity and good rate performance of GDY as a very promising anode material for LIBs. The theoretical capacity of monolayered GDY is $744 \mathrm{mAh} \mathrm{g}^{-1}$, whereas that of multilayered GDY is more than $1000 \mathrm{mAh}^{-1} \cdot{ }^{[8]}$ The actual reversible capacity of GDY film reaches only $612 \mathrm{mAhg}^{-1}$ at a current density of $100 \mathrm{~mA} \mathrm{~g}^{-1}$ in a practical LIB, which is lower than that predicted. ${ }^{[6]}$ This motived us to seek improvements for applying GDY in electrode materials.

[a] Dr. J. He, J. Yu, Prof. C. Huang, X. Shen, Dr. Z. Cui, Dr. N. Wang Qingdao Institute of Bioenergy and Bioprocess Technology

Chinese Academy of Sciences, No. 189 Songling Road

Qingdao 266101 (P.R. China)

E-mail:huangcs@qibebt.ac.cn

[b] K. Bao

Qingdao University of Science and Technology

No. 53 Zhengzhou Road, Qingdao 266042 (P.R. China)

[c] W. Cui

Qingdao University, No. 308 Ningxia Road, Qingdao 266071 (P.R. China)

$\square$ Supporting information and the ORCID identification numbers for the au-

(iD thors of this article can be found under https://doi.org/10.1002/ chem. 201704581
It is reported that the good interfacial compatibility between the bulk electrode material and electrolyte is beneficial for good electrochemical performance. ${ }^{[9]}$ The construction of GDY with uniform morphology and interface compatibility is meaningful for the application of GDY in LIBs. ${ }^{[10]}$ Because the synthesis of GDY is mainly achieved through a Glaser coupling reaction, considering that GDY is a $2 \mathrm{D}$ planar structure, the fast chemical reaction will also result in some small-molecule pieces of GDY, such as its oligomers, as well as defects and some amorphous phase, which may affect the quality of GDY, its interface compatibility, and electrochemical performance. It is reported that the structural development of carbon materials during heat treatment is a thermally activated kinetic process. ${ }^{[9,11]}$ Kim et al. reported that a high-purity carbon nanofiber web, which was thermally treated at $2800^{\circ} \mathrm{C}$ in an inert atmosphere, displayed a morphological transformation from a smooth to a wrinkled surface. ${ }^{[9]}$ Wang et al. introduced uniform graphene nanosheets prepared by a rapid heating process and subsequent ultrasonic treatment. ${ }^{[11 c]}$ For us, heat treatment, including the annealing method, may pave the way to improving the quality of film and bulk GDY because heat treatment may remove oligomers, provide conditions for self-repairing the defects and flaws of GDY, and improve the interfacial compatibility of GDY.

Herein, we report on the construction of large-area uniform GDY films through heat treatment. SEM and TEM images of GDY films reveal the uniform morphology and demonstrate the evolution process. The UV/Vis absorption spectrum and $I-V$ curves suggest the preparation of GDY films with good conductivity after the cross-coupling reaction. Benefitting from the uniform interface and good conductivity, the GDY film exhibits a highly improved reversible capacity of $901 \mathrm{mAhg}^{-1}$ for LIBs 
at a current density of $100 \mathrm{mAg}^{-1}$. Remarkably, this uniform film still maintains a capacity of $430 \mathrm{mAhg}^{-1}$ at a rate as high as $5 \mathrm{Ag}^{-1}$.

\section{Results and Discussion}

\section{Morphological and structural evolution of GDY films}

We performed heat treatment on fabricated GDY at different temperatures for different time periods (Figure S1 in the Supporting Information). It is observed in the thermogravimetric (TG) profile that the fabricated GDY manifests continuous weight loss until $600^{\circ} \mathrm{C}$, which suggests the existence of oligomers (Figure S2 in the Supporting Information). The heat-treatment process and results were observed by SEM. The SEM images show that there are many GDY nanoparticles, which are about $700 \mathrm{~nm}$ in diameter, on the surface of GDY film after calcination at $200^{\circ} \mathrm{C}$ for $2 \mathrm{~h}$ (Figure $1 \mathrm{a}$ ). Magnification shows that the film is composed of melted nanoparticles. It can be seen from Figure $1 \mathrm{~b}$ that some of the nanoparticles are eliminated during calcination at $300^{\circ} \mathrm{C}$ for $2 \mathrm{~h}$. Meanwhile, the jagged and porous surface shown in Figure $1 \mathrm{~b}$ reveals that many embedded oligomers and particles with a low gasification temperature in the bulk of the GDY films evaporate under heat treatment. These results indicate that the evolution of GDY films is dominated by an evaporation process at a heating temperature of 200 and $300^{\circ} \mathrm{C}$. As the heating temperature increased to $400^{\circ} \mathrm{C}$, most nanoparticles were removed from the surface to construct uniform and smooth GDY films (Fig-
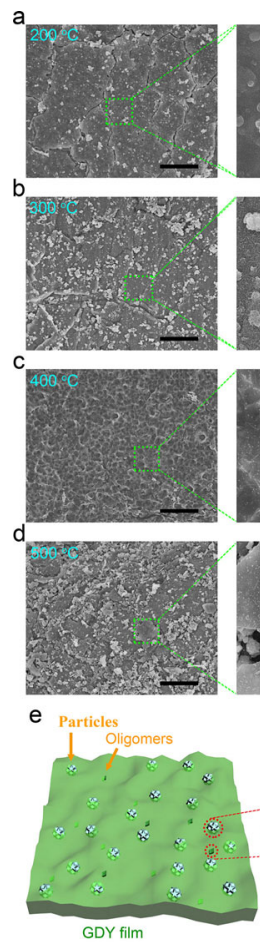

GDY film
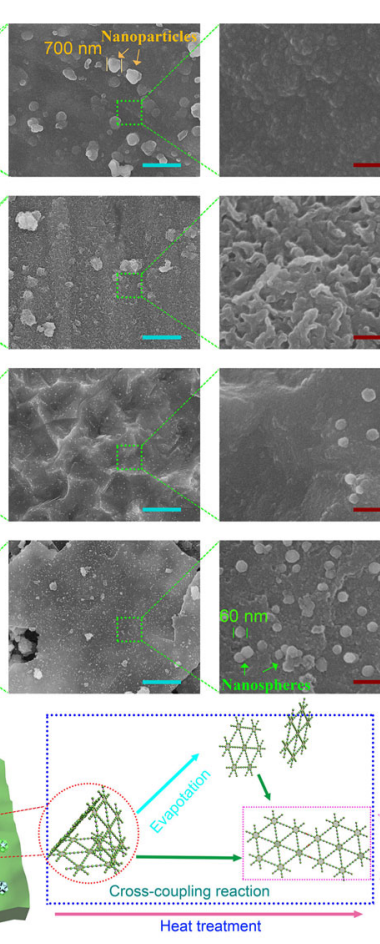
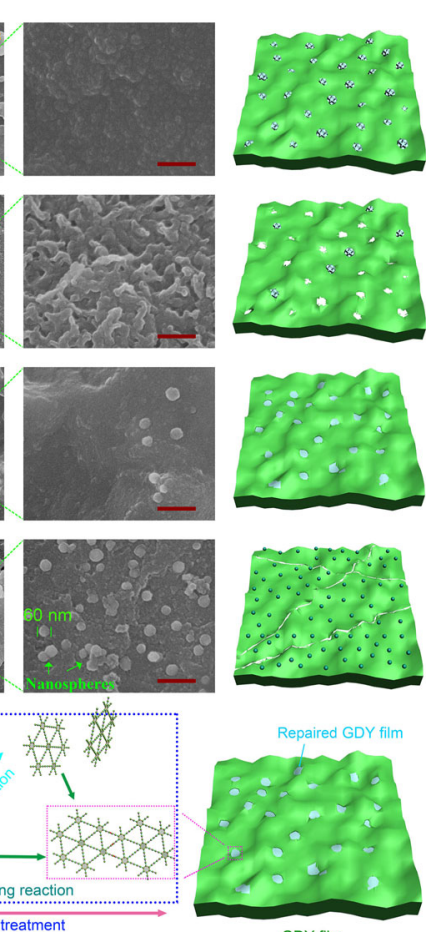

GDY film
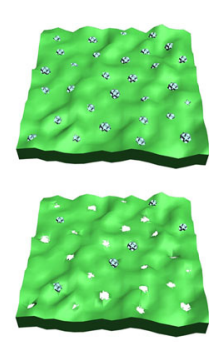

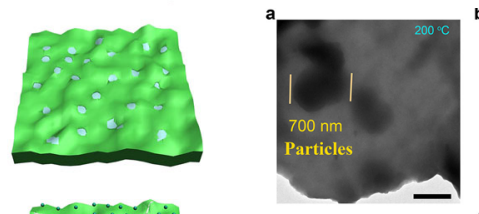

Figure 1. SEM images of GDY heated at different temperatures: a) heated at $200^{\circ} \mathrm{C}$ for $\left.2 \mathrm{~h}, \mathrm{~b}\right)$ heated at $300^{\circ} \mathrm{C}$ for $2 \mathrm{~h}, \mathrm{c}$ ) heated at $400^{\circ} \mathrm{C}$ for $2 \mathrm{~h}$, and d) heated at $500^{\circ} \mathrm{C}$ for $2 \mathrm{~h}$. Scale bars: $20 \mu \mathrm{m}$ (black), $2 \mu \mathrm{m}$ (green), $200 \mathrm{~nm}$ (red). e) The proposed growth mechanism of uniform GDY film.
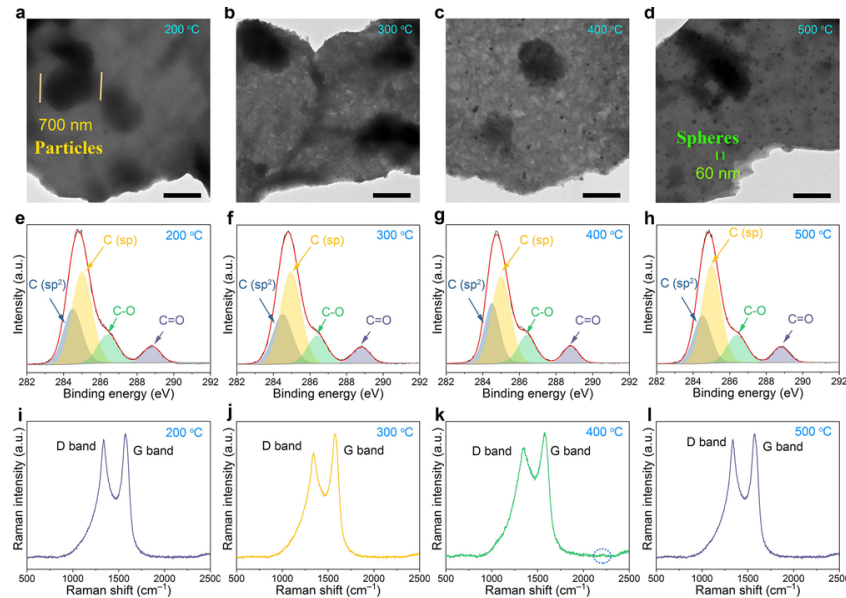

ure 1c). This process may be attributed to both evaporation of oligomers and some self-repair process, in which the crosscoupling reaction takes place on small pieces and defects of the GDY film surface. ${ }^{[12]}$ The proposed growth mechanism of the uniform film is illustrated in Figure $1 \mathrm{e}$. The GDY nanoparticles either take part in the cross-coupling reaction or evapothe surface of GDY. However, uniform films are broken and many GDY nanospheres, with a diameter of $60 \mathrm{~nm}$, emerge at a heating temperature of $500^{\circ} \mathrm{C}$ (Figure $1 \mathrm{~d}$ ). This phenomenon can be explained because the morphology of generated GDY is prone to form spheres, rather than films, to reduce the surface energy at high temperatures. ${ }^{[13]}$

The evolution of the GDY morphology at different temperatures can also be observed in the TEM images in Figure $2 \mathrm{a}-\mathrm{d}$. Stacked layers are observed in all samples, which suggests the 2D structure of GDY films. The GDY particles are distinguishable in the TEM images in Figure $2 a-d$, which is consistent with the results in SEM images (Figure $1 \mathrm{a}-\mathrm{d}$ ). Figure $2 \mathrm{a}$ shows the sample treated at $200^{\circ} \mathrm{C}$. The GDY film was compact without clear pores, whereas at $300^{\circ} \mathrm{C}$ the GDY film revealed a porous structure (Figure $2 \mathrm{~b}$ ), which confirmed evaporation of the GDY oligomers. At $400^{\circ} \mathrm{C}$ (Figure $2 \mathrm{C}$ ), the porous structure is clearer have evaporated, which would benefit a high surface area. This porous structure is not observed in the SEM images (Figure 1c), which suggests that the self-repair reaction preferentially occurs at the surface, rather than in the bulk, because of sufficient evaporation of oligomers from the surface. The porous structure decreased to a small piece of the GDY film if the temperature was raised to $500^{\circ} \mathrm{C}$ (Figure $2 \mathrm{~d}$ ). This phenenon can be ascribed to the broken bulk film, and consequently, facilitation of the self-repair reaction in more regions. The chemical structure was characterized by XPS (Figure $2 \mathrm{e}-$ in Figure $2 \mathrm{e}-\mathrm{h}$ that there is no significant change between any of the samples treated at different temperatures, or those that

Figure 2. TEM images (a-d), X-ray photoelectron spectroscopy (XPS) results $(e-h)$, and Raman spectra (i-l) of heat-treated GDY at different temperatures: a) treated at $200^{\circ} \mathrm{C}$ for $\left.2 \mathrm{~h}, \mathrm{~b}\right)$ treated at $300^{\circ} \mathrm{C}$ for $2 \mathrm{~h}, \mathrm{c}$ ) treated at $400^{\circ} \mathrm{C}$ for $2 \mathrm{~h}$, and d) treated at $500^{\circ} \mathrm{C}$ for $2 \mathrm{~h}$. Scale bars: $500 \mathrm{~nm}$. 
are untreated, which implies that the main structure of the samples does not change after heat treatment under argon (Figure S4a in the Supporting Information). In detail, the $\mathrm{C} 1 \mathrm{~s}$ peaks of GDY in Figure $2 \mathrm{e}-\mathrm{h}$ can be deconvoluted into four subpeaks of $\mathrm{C}-\mathrm{C}\left(\mathrm{sp}^{2}\right)$ at $284.5 \mathrm{eV}, \mathrm{C}-\mathrm{C}(\mathrm{sp})$ at $285 \mathrm{eV}, \mathrm{C}-\mathrm{O}$ at $286.4 \mathrm{eV}$, and $\mathrm{C}=\mathrm{O}$ at $288.8 \mathrm{eV}$. XPS data shows that the synthetic products have both $\mathrm{sp}^{2}$ - and $\mathrm{sp}$-hybridized carbon, and the area ratio of the two is close to $1: 2$, which is consistent with the reported structure. ${ }^{[14]}$ In the fitting peaks of carbon, we have also found a lot of oxygen, which may be because GDY has a high specific surface area and a large number of pores, and thus, has a strong adsorption ability for $\mathrm{O}_{2}$ upon exposure to air. Figure $2 \mathrm{i}-\mathrm{I}$ shows that the Raman spectra of the as-synthesized samples exhibit two main bands. A G band at $1584 \mathrm{~cm}^{-1}$ suggests that the products possess abundant aromatic rings, and a D band at $1356 \mathrm{~cm}^{-1}$ corresponds to defects and edges. ${ }^{[15]}$ It can be observed that the intensity of the $D$ band decreases due to the self-repair reaction. The inconspicuous band at $2200 \mathrm{~cm}^{-1}$ can be observed in Figure $2 \mathrm{k}$, which is assigned to the acetylenic bond. The increasing intensity of the $\mathrm{D}$ band, in comparison with that of untreated GDY, may be due to defects generated at $200^{\circ} \mathrm{C}$ (Figure S4 b in the Supporting Information).

UV/Vis absorption spectroscopy was used to characterize the electronic conductivity of GDY films (Figure S5 in the Supporting Information). The energy gaps between the HOMO and LUMO of the heat-treatment samples were measured to be $1.31 \mathrm{eV}$ for the untreated sample, $1.52 \mathrm{eV}$ for that treated at $200{ }^{\circ} \mathrm{C}, 1.22 \mathrm{eV}$ for that treated at $300^{\circ} \mathrm{C}, 1.02 \mathrm{eV}$ for that treated at $400^{\circ} \mathrm{C}$, and $0.94 \mathrm{eV}$ for that treated at $500^{\circ} \mathrm{C}$ (Figure $3 a) .^{[16]}$ The $I-V$ curves indicate that the conductivity is $2.26 \times 10^{-4}, 1.86 \times 10^{-5}, 6.07 \times 10^{-4}, 2.56 \times 10^{-3}$, and $6.45 \times$ $10^{-3} \mathrm{~S} \mathrm{~m}^{-1}$ for the untreated sample and those heated at 200 , 300,400 , and $500^{\circ} \mathrm{C}$, respectively (Figure $3 \mathrm{~b}$ ). The decreasing energy gap and increasing conductivity with increasing treatment temperature reveals the improved quality of the GDY
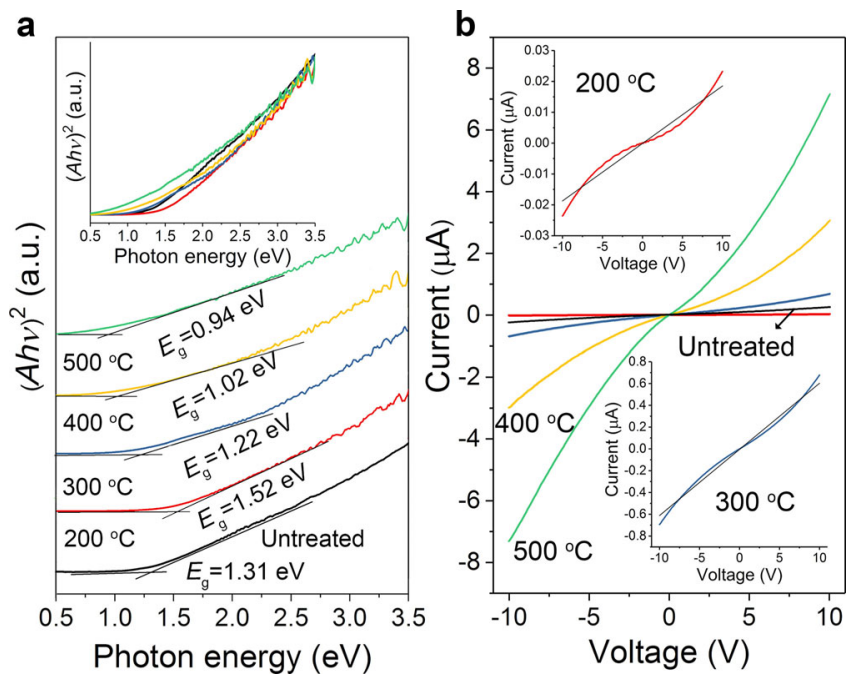

Figure 3. a) Transformation of the UV/Vis spectrum for heat-treated GDY; inset: plots of $(A h v)^{2}$ versus photon energy $(h v)$. b) I-V curves of heat-treated GDY. film; this can be ascribed to the elimination and possible selfrepair cross-coupling process of GDY oligomers and pieces. The slight reduction in conductivity, in comparison with that of untreated GDY, may be ascribed to defects generated upon the evaporation of oligomers at a heating temperature of $200^{\circ} \mathrm{C}$.

The influence of heat-treatment duration on the synthesis of GDY has also been investigated (Figure S6 in the Supporting Information). Particles exist on the surface until GDY has been heated for as long as $2 \mathrm{~h}$ at $400^{\circ} \mathrm{C}$. The formation of the smooth GDY film is clearly observed in Figure $\mathrm{S} 6 \mathrm{~b}$ and e in the Supporting Information; thus the self-repair reaction has occurred. Although the surface of the GDY film becomes smooth, some oligomers exist on it due to the short heating duration (Figure S6a and $d$ in the Supporting Information). The SEM images in Figure $\mathrm{S} 6 \mathrm{a}, \mathrm{d}$, and $\mathrm{g}$ in the Supporting Information demonstrate that the self-repair process is limited by the duration of the cross-coupling reaction and evaporation of oligomers over $2 \mathrm{~h}$. However, uniform GDY spheres emerged as the heating time is prolonged to $3 \mathrm{~h}$, which suggests the instability of the newly formed GDY film morphology over a long heating duration at high temperature (Figure S6j-I in the Supporting Information). As far as the roles of heating temperature and duration in the formation of uniform GDY film are concerned, it can be concluded that a heating temperature of $400^{\circ} \mathrm{C}$ is beneficial for both evaporation and further cross-coupling reaction of oligomers for a heating time of $2 \mathrm{~h}$ to ensure that the self-repair of the GDY film can proceed properly.

The time-dependent GDY film self-repair process at $400{ }^{\circ} \mathrm{C}$ can be clearly observed in the TEM images shown in Figure S7 a-d in the Supporting Information. The porous structure can be clearly observed in the samples treated for $0.5,1$, and $2 \mathrm{~h}$. This phenomenon demonstrates that the evaporation of oligomers takes place in the bulk film. The evolution of the particles is clearly realized. There are many particles on the surface of the formed uniform film heated for 0.5 and $1 \mathrm{~h}$ (Figure $57 \mathrm{a}$ and $\mathrm{b}$ in the Supporting Information). These particles are eliminated as heating continues for $2 \mathrm{~h}$ (Figure S7 $\mathrm{c}$ in the Supporting Information). Nevertheless, GDY spheres emerge because they are energetically favorable as the heating duration is prolonged to $3 \mathrm{~h}$ (Figure S7 $\mathrm{d}$ in the Supporting Information). XPS spectra demonstrate that the position of the four subpeaks and the area ratio of $\mathrm{sp}^{2}$ - and $\mathrm{sp}$-hybridized carbon does not change for different heating durations, which suggests that the chemical structure does not evolve during the heat-treatment process (Figures S7e and S8 in the Supporting Information). As shown in Figure S7 $f$ in the Supporting Information, Raman spectra also reveal a comparable intensity between $D$ and $G$ bands in all samples. The result is consistent with that at different temperatures, which reveals a stable chemical structure throughout the heating process. The energy gaps of the samples heated for different times were calculated by the transformation of UV/Vis absorption spectra (Figures S7g and S9 in the Supporting Information). The energy gaps of the samples evolved from 1.16, 1.11, 1.02 to $0.96 \mathrm{eV}$ as the samples were heated for $0.5,1,2$, and $3 \mathrm{~h}$, respectively, at $400^{\circ} \mathrm{C}$. The $I-V$ curves in Figure $S 7 \mathrm{~h}$ in the Sup- 
porting Information show that the conductivity of the samples is calculated to be $8.93 \times 10^{-4}, 1.19 \times 10^{-3}, 2.56 \times 10^{-3}$, and $4.84 \times 10^{-3} \mathrm{Sm}^{-1}$ for the samples heated $0.5,1,2$, and $3 \mathrm{~h}$ at $400^{\circ} \mathrm{C}$. The similar values of conductivities indicate the occurrence of similar self-repair reactions, regardless of heating duration. These results demonstrate that the heating duration plays an important role in the further execution of the thermal cross-coupling reaction of GDY oligomers and pieces.

\section{Electrochemical performance of GDY films}

The electrochemical performances of the GDY film electrodes were evaluated by using half-cells with lithium metal as a reference electrode over the potential range of $0.005-3 \mathrm{~V}$ versus $\mathrm{Li}^{+} / \mathrm{Li}$. Figure $4 \mathrm{a}-\mathrm{d}$ shows the rate performance of electrodes composed of the GDY film treated at different temperatures from 0.1 to $5 \mathrm{Ag}^{-1}$. All electrodes, except the sample heated at $500^{\circ} \mathrm{C}$, can recover from the high current density and show a decent rate performance. It can be clearly observed that the reversible capacity is different at a current density of $100 \mathrm{mAg}^{-1}$ for different heating temperatures (Figure $4 \mathrm{a}-\mathrm{d}$ ). The initial Coulombic efficiency (CE) of the electrodes is 58.8, 44.0, 44.7, and $50.8 \%$ for the samples heated at 200, 300, 400, and $500^{\circ} \mathrm{C}$, respectively. The reversible capacity increases with increasing heating temperature from 200 to $400^{\circ} \mathrm{C}$ because of the increasing conductivity. The lower reversible capacity of samples heated at 200 and $300^{\circ} \mathrm{C}$ is ascribed to the existence of oligomers and particles, which exhibit a low conductivity,
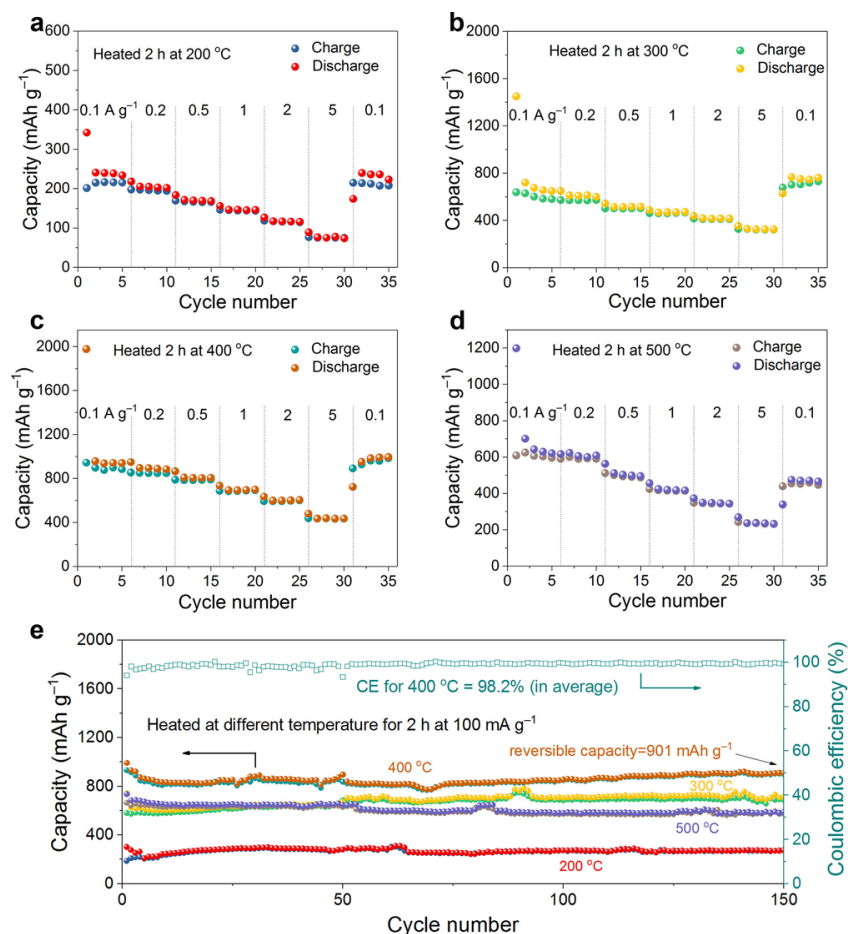

Figure 4. The rate performance of heat-treated GDY at different temperatures: a) treated at $200{ }^{\circ} \mathrm{C}$ for $2 \mathrm{~h}, \mathrm{~b}$ ) treated at $300^{\circ} \mathrm{C}$ for $2 \mathrm{~h}, \mathrm{c}$ ) treated at $400^{\circ} \mathrm{C}$ for $2 \mathrm{~h}$, and d) treated at $500^{\circ} \mathrm{C}$ for $2 \mathrm{~h}$. e) The cycling performance of heat-treated GDY at different temperatures; the current density is $100 \mathrm{mAg}^{-1}$. and thus, limited active binding sites. ${ }^{[17]}$ However, the reversible capacity starts to reduce as the heating temperature rises to $500^{\circ} \mathrm{C}$. This phenomenon may be ascribed to poor diffusion of lithium ions through the newly generated GDY spheres and compact sheets, in spite of better conductivity at $500^{\circ} \mathrm{C}$. It can be seen from Figure S10 in the Supporting Information that the Galvanostatic charge/discharge curves of samples heated for $2 \mathrm{~h}$ at different temperatures are similar to each other; this indicates that there are no clear redox peaks, which is consistent with previous work. ${ }^{[6]}$ Figure $4 \mathrm{e}$ shows the cyclic stabilities of different samples. The samples show good cycle performance, except for the one heated at $500^{\circ} \mathrm{C}$. The reversible capacity can reach $272,689,901$, and $578 \mathrm{mAhg}^{-1}$ for heattreated samples at $200,300,400$, and $500^{\circ} \mathrm{C}$ after 150 cycles at a current density of $100 \mathrm{mAg}^{-1}$. The low reversible capacity of the free-standing film treated at $200^{\circ} \mathrm{C}$ is due to the lack of conductivity or current collectors, in comparison with the reported untreated GDY. ${ }^{[6]}$

The CE of the sample heated at $400^{\circ} \mathrm{C}$ is about $98.2 \%$, on average. The different cycle performance between the samples heated at 400 and $500^{\circ} \mathrm{C}$ suggests that the uniform film is beneficial for good electrochemical stability, which is dominated by the interfacial reaction. The reversible capacity of GDY heated at $400^{\circ} \mathrm{C}$ is higher than that of most carbon materials, including GDY on copper foil, natural graphite (NG), carbon nanotubes (CNTs), graphene, and comparable to that of $\mathrm{N}$ doped porous carbon nanofibers (N-CNFs) and hollow CNTs/ CNFs in LIBs (Table 1). Although a much higher capacity is obtained for $\mathrm{N}$-doped porous carbon, it always suffers from instability due to the high amount of defects. In addition, GDY films treated at different temperatures exhibit superior cyclic stability to that of graphene sheets, which contain abundant edges due to the synthetic route. ${ }^{[11 c]}$

Interfacial charge transfer and the lithium-ion diffusion process in the electrode were characterized by SEM and electrochemical impedance spectroscopy (EIS). Figure $5 \mathrm{a}-\mathrm{d}$ shows the SEM images of the formed solid-electrolyte interface (SEI) film

\begin{tabular}{|lcll|}
\hline Table 1. Reversible capacities of carbon materials as anodes in LIBs. \\
Electrode & $\begin{array}{l}\text { Reversible } \\
\text { capacity }\left[\mathrm{mAhg}^{-1}\right]\end{array}$ & $\begin{array}{l}\text { Discharge } \\
\text { rate }\end{array}$ & Ref. \\
\hline GDY film & 901 & $100 \mathrm{mAg}^{-1}$ & this \\
GDY film & & & work \\
& 807 & $500 \mathrm{mAg}^{-1}$ & this \\
GDY on Cu & & & work \\
NG & 612 & $100 \mathrm{mAg}^{-1}$ & {$[6]$} \\
CNT & 360 & $15 \mathrm{mAg}^{-1}$ & {$[18]$} \\
hard carbon & 200 & $400 \mathrm{mAg}^{-1}$ & {$[19]$} \\
graphene & 424 & $30 \mathrm{mAg}^{-1}$ & {$[20]$} \\
N-graphene & 460 & $1 \mathrm{C}^{-1}$ & {$[11 \mathrm{c}]$} \\
B-graphene & 872 & $50 \mathrm{mAg}^{-1}$ & {$[21]$} \\
3D graphene & 700 & $500 \mathrm{mAg}^{-1}$ & {$[21]$} \\
N-CNTs & 659 & $0.5 \mathrm{C}^{-1}$ & {$[22]$} \\
N-CNFs & 516 & $200 \mathrm{mAg}^{-1}$ & {$[23]$} \\
N-CNFs & 1280 & $100 \mathrm{mAg}^{-1}$ & {$[24]$} \\
hollow CNTs/CNFs & 924 & $500 \mathrm{mAg}^{-1}$ & {$[24]$} \\
N-doped porous carbon & 1150 & $100 \mathrm{mAg}^{-1}$ & {$[25]$} \\
\end{tabular}



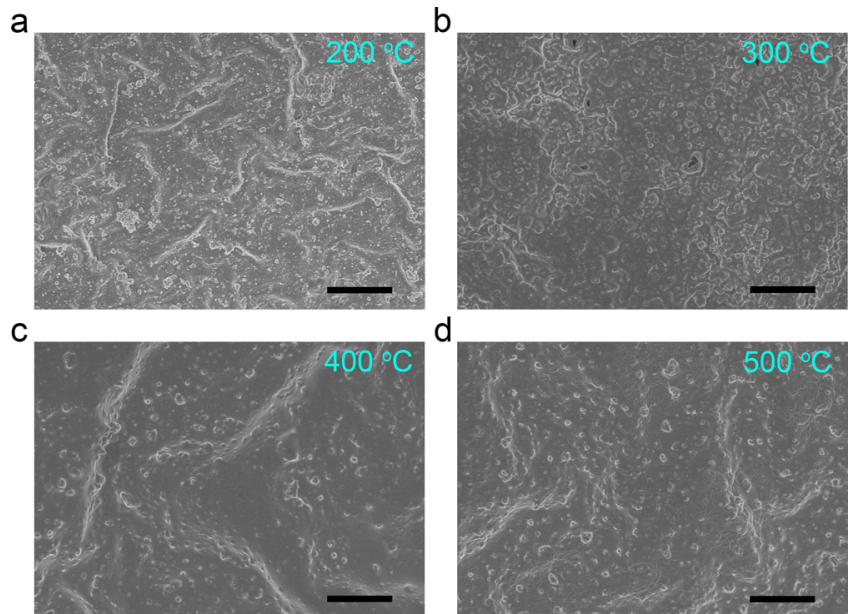

d

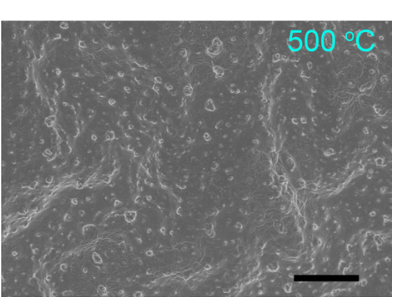

e

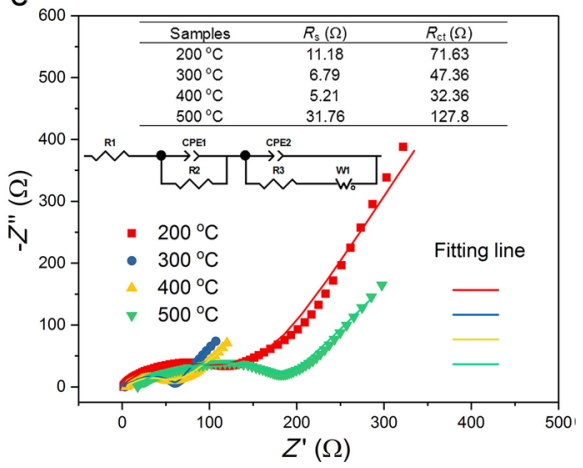

Figure 5. SEM images of heat-treated GDY at different temperatures for LIBs after cycling: a) treated at $200^{\circ} \mathrm{C}$ for $2 \mathrm{~h}, \mathrm{~b}$ ) treated at $300^{\circ} \mathrm{C}$ for $2 \mathrm{~h}, \mathrm{c}$ ) treated at $400^{\circ} \mathrm{C}$ for $2 \mathrm{~h}$, and d) treated at $500^{\circ} \mathrm{C}$ for $2 \mathrm{~h}$. Scale bars: $20 \mu \mathrm{m}$. e) EIS of the electrodes after cycling; inset shows the equivalent circuit and fitting parameters. $\mathrm{CPE}=$ constant-phase element.

on samples heated at different temperatures. The SEI film of the sample heated at $400^{\circ} \mathrm{C}$ is more uniform than that of the others. High-resolution TEM was performed on GDY films heated at 300 and $400{ }^{\circ} \mathrm{C}$ before and after lithium intercalation; these results demonstrated changes in the layer distance. It can be observed from Figure S11 in the Supporting Information that the layer distance of heated GDY films is about $0.365 \mathrm{~nm}$, which is consistent with untreated GDY. Furthermore, the layer ordering is almost maintained after cycling. This good interfacial compatibility can also be observed in the EIS results. The equivalent circuit model of the studied system can be observed in Figure $5 \mathrm{e}$. The indistinct semicircle in the high-frequency region corresponds to the SEI film resistance $\left(R_{\mathrm{s}}\right)$ and the constant-phase element (CPE1), the medium-frequency semicircle is assigned to the charge-transfer impedance $\left(R_{\mathrm{ct}}\right)$ and the CPE of the electrode-electrolyte interface (CPE2), and $W$ in the low-frequency region is associated with the Warburg impedance. ${ }^{[27]}$ The fitting parameters are listed in the inset of Figure $5 \mathrm{e}$. The low $R_{\mathrm{s}}$ and $R_{\mathrm{ct}}$ values of the sample heated at $400^{\circ} \mathrm{C}$ suggest good interface contact between the uniform GDY film and SEI film, which would minimize side reactions.

Figure S12 in the Supporting Information shows the electrochemical performance of the as-synthesized samples heated for different times. The rate performance of the samples treated at $400^{\circ} \mathrm{C}$ for different times is similar to that of samples treated at different temperatures. However, the samples heated at $400^{\circ} \mathrm{C}$ exhibited superior reversible capacity than that of the sample heated at $200^{\circ} \mathrm{C}$ due to good conductivity. The sample heated for $0.5 \mathrm{~h}$ at $400^{\circ} \mathrm{C}$ shows a lower capacity than that of the others; this can be ascribed to the existence of numerous oligomers. The extremely similar electrochemical behavior between the samples heated for 1 and $2 \mathrm{~h}$ at $400^{\circ} \mathrm{C}$ contributes to the similar morphology and interfacial contact (Figure S6 in the Supporting Information). The sample heated for $3 \mathrm{~h}$ delivers rapid degradation of capacity because of the GDY spheres; this is consistent with the results observed in Figure $4 \mathrm{~d}$. Galvanostatic charge/discharge curves of samples heated for different times are shown in Figure S13 in the Supporting Information and reveal the analogical electrochemical process in these samples. The cycle performance of the samples heated at $400{ }^{\circ} \mathrm{C}$ for different times is depicted in Figure $\mathrm{S} 12 \mathrm{e}$ in the Supporting Information. Reversible capacities of $257,658,807$, and $345 \mathrm{mAhg}^{-1}$ are achieved for samples treated at $400^{\circ} \mathrm{C}$ for $0.5,1,2$, and $3 \mathrm{~h}$ at a current density of $500 \mathrm{~mA} \mathrm{~g}^{-1}$ after 300 cycles. Excellent cycling stability can be observed for the electrochemical performance of samples heated for $0.5,1$, and $2 \mathrm{~h}$. Specifically, the CE of the sample heated at $400{ }^{\circ} \mathrm{C}$ for $2 \mathrm{~h}$ is as high as $99.8 \%$.

It can be observed from Figure S14a-d in the Supporting Information that GDY particles or spheres influence the formation of a uniform SEl film. Broken films in Figure S14a and d in the Supporting Information suggest an unstable interface, as characterized by EIS. Figure S14e in the Supporting Information shows Nyquist plots of samples heated for different times at $400{ }^{\circ} \mathrm{C}$; the equivalent circuit and fitting parameters are also listed. Samples heated for 0.5 and $3 \mathrm{~h}$ at $400^{\circ} \mathrm{C}$ have a large interfacial resistance due to the existence of GDY particles and spheres. The low resistance and uniform morphology of the SEl film for both samples heated for 1 and $2 \mathrm{~h}$ are beneficial for the reduction of the interfacial reaction, which results in a superior rate performance and cycling stability.

\section{Conclusion}

Improved uniform GDY film was prepared by a thermal method. SEM and TEM images revealed that the heating temperature played important roles in both the evaporation of oligomers and triggering of the thermal cross-coupling reaction, whereas the heating duration mainly determined execution of the thermal cross-coupling reaction. Through the optimization of both factors, large-area uniform GDY film was obtained that demonstrated good interface contact, as evidenced by SEM images after cycling and EIS. Furthermore, good conductivity was achieved through the cross-coupling of oligomers. These advantages endow the improved uniform GDY film with excellent electrochemical behavior, including large reversible capacity, good rate, and stable cycling performance. 


\section{Experimental Section}

\section{Synthesis}

GDY films were obtained through the synthetic route described in ref. [6] followed by heat treatment under an argon atmosphere (Figure 1). The heating temperature was from 200 to $500^{\circ} \mathrm{C}$ and heating was maintained at the required temperature for $2 \mathrm{~h}$. Furthermore, samples were heated for different times at $400^{\circ} \mathrm{C}$. The heating rate was $5^{\circ} \mathrm{Cmin}^{-1}$ and samples were cooled to room temperature spontaneously. A detailed synthetic method is given in the Supporting Information.

\section{Characterization}

Morphology details were examined by means of field-emission SEM (HITACHI S-4800) and TEM (HITACHI H-7650). The chemical structure of the samples was characterized by Raman spectroscopy (Thermo Scientific DXRxi, $532 \mathrm{~nm}$ ). XPS results were collected on a VG Scientific ESCALab220i-XL X-ray photoelectron spectrometer, with $\mathrm{Al}_{\mathrm{K} \alpha}$ radiation as the excitation source. UV/Vis adsorption spectroscopy was recorded on a HITACHI U-4100 spectrometer. The $I-V$ curves were measured on a Keithley 4200 SCS instrument. A Rubotherm DynTHERM instrument was used to perform TG analysis.

\section{Electrochemical analysis}

Electrochemical measurements were performed by using CR2032 coin-type cells assembled in an argon-filled glovebox. The half-cells were assembled by using the GDY films as the cathode, Li metal foil as the anode, a polypropylene separator (Celgard 2500), and a liquid electrolyte (ethylene carbonate/dimethyl carbonate, 1:1 v/v) containing $1.0 \mathrm{M} \mathrm{LiPF} 6$ for LIBs were used. The assembled half-cells were cycled between 0.005 and $3 \mathrm{~V}$ by using a LAND battery testing system. EIS measurements were carried out on a CHI760 electrochemical work station from $\mathrm{CH}$ Instruments by applying an alternating current $(\mathrm{AC})$ voltage with an amplitude of $5 \mathrm{mV}$ at room temperature.

\section{Acknowledgements}

This study was supported by the National Natural Science Foundation of China (21790050, 21790051, 21771187), the Hundred Talents Program and Frontier Science Research Project (QYZDB-SSW-JSC052) of the Chinese Academy of Sciences, and the Natural Science Foundation of Shandong Province (P.R. China) for Distinguished Young Scholars (JQ201610).

\section{Conflict of interest}

The authors declare no conflict of interest.

Keywords: electrochemistry · graphdiyne · lithium • surface analysis $\cdot$ thin films

[1] a) J. Li, X. Gao, B. Liu, Q. Feng, X. B. Li, M. Y. Huang, Z. Liu, J. Zhang, C. H. Tung, L. Z. Wu, J. Am. Chem. Soc. 2016, 138, 3954; b) S. Wang, L. Yi, J. E. Halpert, X. Lai, Y. Liu, H. Cao, R. Yu, D. Wang, Y. Li, Small 2012, 8, 265; c) N. Yang, Y. Liu, H. Wen, Z. Tang, H. Zhao, Y. Li, D. Wang, ACS
Nano 2013, 7, 1504; d) X. Gao, J. Li, R. Du, J. Zhou, M. Y. Huang, R. Liu, J. Li, Z. Xie, L. Z. Wu, Z. Liu, Adv. Mater. 2016, 28, 1605308.

[2] a) R. Liu, H. Liu, Y. Li, Y. Yi, X. Shang, S. Zhang, X. Yu, S. Zhang, H. Cao, G. Zhang, Nanoscale 2014, 6, 11336; b) H. Qi, P. Yu, Y. Wang, G. Han, H. Liu, Y. Yi, Y. Li, L. Mao, J. Am. Chem. Soc. 2015, 137, 5260.

[3] a) J. Xiao, J. Shi, H. Liu, Y. Xu, S. Lv, Y. Luo, D. Li, Q. Meng, Y. Li, Adv. Energy Mater. 2015, 5, 1401943; b) H. Ren, H. Shao, L. Zhang, D. Guo, Q. Jin, R. Yu, L. Wang, Y. Li, Y. Wang, H. Zhao, D. Wang, Adv. Energy Mater. 2015, 5, 1500296; c) C. Kuang, G. Tang, T. Jiu, H. Yang, H. Liu, B. Li, W. Luo, X. Li, W. Zhang, F. Lu, J. Fang, Y. Li, Nano Lett. 2015, 15, 2756.

[4] X. Gao, J. Zhou, R. Du, Z. Xie, S. Deng, R. Liu, Z. Liu, J. Zhang, Adv. Mater. 2016, 28, 168.

[5] H. Du, H. Yang, C. Huang, J. He, H. Liu, Y. Li, Nano Energy 2016, 22, 615.

[6] C. Huang, S. Zhang, H. Liu, Y. Li, G. Cui, Y. Li, Nano Energy 2015, 11, 481.

[7] a) S. Zhang, J. He, J. Zheng, C. Huang, Q. Lv, K. Wang, N. Wang, Z. Lan, J. Mater. Chem. A 2017, 5, 2045; b) S. Zhang, H. Liu, C. Huang, G. Cui, Y. Li, Chem. Commun. 2015, 51, 1834; c) S. Zhang, H. Du, J. He, C. Huang, H. Liu, G. Cui, Y. Li, ACS Appl. Mater. Interfaces 2016, 8, 8467.

[8] a) C. Sun, D. J. Searles, J. Phys. Chem. C 2012, 116, 26222; b) H. J. Hwang J. Koo, M. Park, N. Park, Y. Kwon, H. Lee, J. Phys. Chem. C 2013, 117, 6919.

[9] C. Kim, K. S. Yang, M. Kojima, K. Yoshida, Y. J. Kim, Y. A. Kim, M. Endo, Adv. Funct. Mater. 2006, 16, 2393.

[10] R. Raccichini, A. Varzi, S. Passerini, B. Scrosati, Nat. Mater. 2015, 14, 271.

[11] a) P. A. Thrower, Chemistry and Physics of Carbon, CRC, Boca Raton, 1996; b) P. Guo, H. Song, X. Chen, Electrochem. Commun. 2009, 11, 1320; c) G. Wang, X. Shen, J. Yao, J. Park, Carbon 2009, 47, 2049.

[12] a) X. Qian, Z. Ning, Y. Li, H. Liu, C. Ouyang, Q. Chen, Y. Li, Dalton Trans. 2012, 41, 730; b) X. Qian, H. Liu, C. Huang, S. Chen, L. Zhang, Y. Li, J. Wang, Y. Li, Sci. Rep. 2015, 5, 7756; c) J. Zhou, X. Gao, R. Liu, Z. Xie, J. Yang, S. Zhang, G. Zhang, H. Liu, Y. Li, J. Zhang, Z. Liu, J. Am. Chem. Soc. 2015, 137, 7596.

[13] a) L. Xiao, J. Damien, J. Luo, H. D. Jang, J. Huang, Z. He, J. Power Sources 2012, 208, 187; b) J. He, C. Niu, C. Yang, J. Wang, X. Su, RSC Adv. 2014, 4, 60253.

[14] G. Li, Y. Li, H. Liu, Y. Guo, Y. Li, D. Zhu, Chem. Commun. 2010, 46, 3256.

[15] a) S. Zhang, J. Wang, Z. Li, R. Zhao, L. Tong, Z. Liu, J. Zhang, Z. Liu, J. Phys. Chem. C 2016, 120, 10605; b) J. Wang, S. Zhang, J. Zhou, R. Liu, R. Du, H. Xu, Z. Liu, J. Zhang, Z. Liu, Phys. Chem. Chem. Phys. 2014, 16, 11303; C) A. C. Ferrari, D. M. Basko, Nat. Nanotechnol. 2013, 8, 235.

[16] T. Yu, B. Lim, Y. Xia, Angew. Chem. Int. Ed. 2010, 49, 4484; Angew. Chem. 2010, 122, 4586.

[17] a) J. Liu, K. Song, C. Zhu, C.-C. Chen, P. A. van Aken, J. Maier, Y. Yu, ACS Nano 2014, 8, 7051; b) B. Wang, X. Li, X. Zhang, B. Luo, M. Jin, M. Liang, S. A. Dayeh, S. T. Picraux, L. Zhi, ACS Nano 2013, 7, 1437.

[18] H. Zheng, K. Jiang, T. Abe, Z. Ogumi, Carbon 2006, 44, $203-210$.

[19] S. W. Lee, N. Yabuuchi, B. M. Gallant, S. Chen, B.-S. Kim, P. T. Hammond, Y. Shao-Horn, Nat. Nanotechnol. 2010, 5, 531-537.

[20] Y.-J. Han, D. Chung, K. Nakabayashi, J.-D. Chung, J. Miyawaki, S.-H. Yoon, Electrochim. Acta 2016, 213, 432-438.

[21] Z.-S. Wu, W. Ren, L. Xu, F. Li, H.-M. Cheng, ACS Nano 2011, 5, $5463-$ 5471.

[22] J. Tang, G. Chen, J. Yang, X. Zhou, L. Zhou, B. Huang, Nano Energy 2014, $8,62-70$.

[23] Z. Pan, J. Ren, G. Guan, X. Fang, B. Wang, S. G. Doo, I. H. Son, X. Huang, H. Peng, Adv. Energy Mater. 2016, 6, 1600271.

[24] L. Qie, W. M. Chen, Z. H. Wang, Q. G. Shao, X. Li, L.X. Yuan, X. L. Hu, W. X. Zhang, Y. H. Huang, Adv. Mater. 2012, 24, 2047-2050.

[25] Y. Chen, X. Li, K. Park, J. Song, J. Hong, L. Zhou, Y.-W. Mai, H. Huang, J. B. Goodenough, J. Am. Chem. Soc. 2013, 135, 16280-16283.

[26] F. Zheng, Y. Yang, Q. Chen, Nat. Commun. 2014, 5, 5261.

[27] J. He, C. Zhang, H. Du, S. Zhang, P. Hu, Z. Zhang, Y. Ma, C. Huang, G. Cui, Electrochim. Acta 2015, 178, 476-483.

Manuscript received: September 27, 2017

Accepted manuscript online: October 26, 2017

Version of record online: $\mathbf{\square} \mathbf{~ u L}, 0000$ 


\section{FULL PAPER}
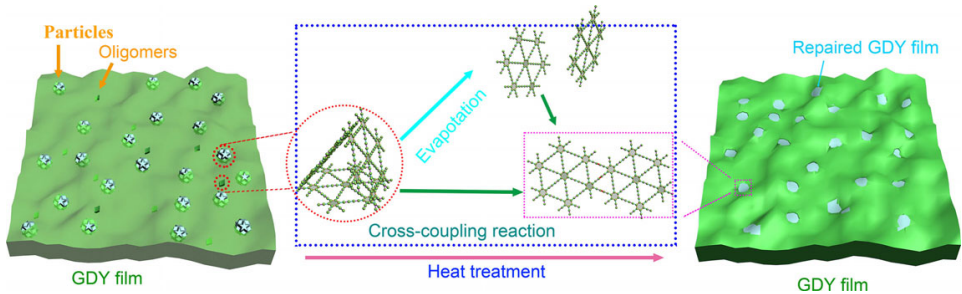

Turn up the heat! A large-area uniform graphdiyne (GDY) film has been constructed through thermal treatment for application in high reversible capacity lithium-ion batteries (see figure). The heating temperature plays an important role in the evaporation of oligomers and in triggering the thermal cross-coupling reaction, whereas the heating duration mainly determines the execution of the thermal cross-coupling reaction.

\section{Synthesis Design}

J. He, K. Bao, W. Cui, J. Yu, C. Huang,* $X$. Shen, Z. Cui, N. Wang Graphdiyne Film for High-Performance
Construction of Large-Area Uniform Lithium-Ion Batteries

\section{a -}

